http://jmscr.igmpublication.org/home/ ISSN (e)-2347-176x ISSN (p) 2455-0450

crossref DOI: https://dx.doi.org/10.18535/jmscr/v8i10.19

Journal Of Medical Science And Clinical Research

\title{
Evaluation of Hepatoprotective Activity of Silymarin in Patients Under Antituberculosis Treatment a Randomized Clinical Trial
}

\author{
Authors \\ Senthilkumar.E ${ }^{1}$, Saravanakumar. $\mathbf{M}^{2}$,Vijai Ananth.P \\ ${ }^{1}$ Post Graduate, Department of Pharmacology, Dhanalakshmi Srinivasan Medical College, Perambalur \\ ${ }^{2}$ Professor and Head, Department of Pharmacology, Dhanalakshmi Srinivasan Medical College, Perambalur \\ ${ }^{3}$ Professor, Department of General Medicine, Dhanalakshmi Srinivasan Medical College, Perambalur
}

\begin{abstract}
Background: Hepatitis is the most serious adverse effect of antitubercular therapy. ${ }^{[1]}$ Silymarin is used as a protective agent in acute and chronic liver disorders ${ }^{[2]}$. We aimed to evaluate the hepatoprotective activity of silymarin in patients receiving antitubercular therapy.

Methods: After getting approval from the institutional human ethics committee and consent from the subjects, this randomized double-blinded placebo-controlled study was conducted. In this study, new cases of pulmonary tuberculosis were divided into two groups. Group 1 was assigned to receive silymarin and Group 2 received a placebo along with Category I antitubercular drugs. The outcome of interest were maximum liver enzymes at week 4 and 8 and the development of anti-TB DILI.

Results: A total of 83 out of 92 expected numbers of patients were enrolled. There were 13/42 (31\%) and $30 / 41$ (73.2\%) patients who developed mild elevation of ALT as well as ALP in the silymarin and the placebo groups $(p<0.001)$ respectively. The mean of ALT levels at week 8 in the silymarin and the placebo group was 29.83(12.7) IU/L and 49.21 (22.29) IU/L ( $<<0.001)$. The mean of ALP levels at week 4 in the silymarin and the placebo group was 58.95(18.43) IU/L and 70.70 (30.40) IU/L ( $p=0.03)$. The mean of AST levels at week 8 in the silymarin and the placebo group was 28.35(12.35) IU/L and 36.70 (14.41) IU/L ( $p=0.007)$.

Conclusion: Silymarin had an effect on reducing ALT, AST, and ALP levels $(P<0.001)$, No serious adverse events were reported. Silymarin is a good choice for the improvement of the liver biochemical profile. Larger clinical trials are required to confirm the result of our study.

Keywords: Tuberculosis, Drug-induced liver injury, Alanine transaminase, Aspartate transaminase, Alkaline phosphatase.
\end{abstract}

\section{Introduction}

Tuberculosis (TB), a disease caused by an infectious agent mycobacterium tuberculosis is the leading cause of death worldwide, surpassing even malaria and HIV. In the year 2016, WHO released a report in which it claimed that nearly 1.4 crore people develop active TB worldwide and around 14 lakh people die every year. ${ }^{[3],[4]}$ For the past 60 years, antibiotics have been implemented in the management of tuberculosis. The prerequisite for 
four antibiotics to be administered for a period of six months imposes a risk of developing adverse effects i.e. gastric, hematological, neurological with hepatotoxicity being the potential side effect. $^{[5],[6],[7]}$ The long duration of treatment along with the likelihood of adverse effects, affects patient compliance reducing the drug efficacy and eventually leading to the emergence of resistance against antitubercular drugs. ${ }^{[7-11]}$ Drug-induced liver injury (DILI) remains the most common adverse effect seen in 2-28\% of the patients on the anti-tubercular drug regimen. ${ }^{[11],[12]}$ resulting in significant morbidity and mortality. ${ }^{[13]}$ DILI causes temporary interruption of anti-tubercular drugs. Treatment is resumed only when recovery is observed on liver function. Hence interventions that help in the normalization of liver function can be implemented.

The DILI working group experts ${ }^{[13]}$ and DILIGEN study ${ }^{[14]}$ implement criteria based on ALP, bilirubin, and ALT to decide on the termination of ATT. Expert recommendation indicates treatment discontinuance if ALT when ALT $>5 x$ ULN. ATS recommends termination if ALT is 3-5xULN and patients showing symptoms like nausea, vomiting, jaundice, and abdominal pain. Each advisory body provides recommendations for drug reintroduction when liver transaminases have normalized. These either recommend sequential re-introduction along with incremental dose increase or re-introduction at full dose. ${ }^{[14],[15]}$

Silymarin, a traditional herbal drug extracted from milk thistle (Silybum marinum) seeds, has been used as a supplement remedy for hepatoprotection. The main components of silymarin comprise silybin, silydianin, silychrisin, and isosilybin. All of these are derivatives of flavonols. Silymarin facilitates hepatoprotection through scavenging of free radicals, thereby reducing oxidative stress, restoring the function of antioxidative enzymes, and generating cell membrane stabilization. Silymarin is used as a protective agent in acute and chronic liver disorders. Silymarin 70mg/140mg Sugar Coated Tablet was approved in India for supportive treatment in chronic liver disease and cirrhosis by CDSCO. In animal models, silymarin showed a protective effect against the hepatotoxicity produced by antitubercular drugs. ${ }^{[2]}$

The hepatoprotective effect of Silymarin in humans treated with antitubercular drugs has not been studied well enough. Hence we performed a study to evaluate the hepatoprotective effect of silymarin in patients receiving anti-tuberculosis treatment.

\section{Aims and Objectives Primary Objective}

- To evaluate the hepatoprotective activity of silymarin in patients receiving category 1 antituberculosis treatment

\section{Secondary Objective}

- Any symptoms or sign related to silymarin drug causing adverse effects

\section{Tertiary Objective}

- To analyze the socio-economic characteristics of the study population

\section{Materials and Methods}

Study design: A prospective double-blinded placebo-controlled study was conducted to evaluate the hepatoprotective activity of silymarin in patients receiving anti-tuberculosis treatment.

Study Location: This study was conducted in the TB \& Chest medicine department of Dhanalakshmi Srinivasan medical college and hospital, a tertiary care teaching hospital under Dr. M.G.R Medical University, Peramabalur, Tamilnadu, India.

Study Period: The study was conducted from January 2019 to January 2020.

Sample Size: The sample size was calculated based on the comparison of mean serum alanine transaminase level between silymarin and placebo. The mean serum ALT was recorded in the previous study after receiving anti-tubercular treatment was $463(\mathrm{SD}=69)$ IU/L. We believed that silymarin works properly, it should be possible to lower the serum ALT level of at least 
10\%. 70 subjects in total were required (35 for each treatment group) to detect the difference by using $80 \%$ power and 5\% type I error. Considering the loss of a $10 \%$ follow-up a total of 80 subjects were required.

Inclusion Criteria: Patients who met the following criteria were enrolled in the study.

1. Newly diagnosed pulmonary tuberculosis patients

2. Age group between 18 to 60 years

3. Both sexes

4. Received category I anti-tubercular drugs

5. Giving informed consent and willing to follow up

\section{Exclusion Criteria}

1. Patients with concomitant HIV, HBV, or HCV infection

2. Preexisting liver disease,

3. Abnormal liver function tests (LFT) prior to anti-tubercular treatment

4. Pregnant and nursing mothers

5. Diabetes mellitus

6. Hypertension

7. Patients receiving chronic medication

Ethical Approval: The study protocol was approved by Institutional Ethics Committee (IECHS/DSMCH/102). It was carried out according to the Good Clinical Practice Guideline.

\section{Randomization and Blinding Methods: By}

implementing a computerized based randomization technique with a block at 10:10, the patients recruited for the analysis were allocated to groups by the statistician. The randomization list was enclosed in an opaque envelope. The patients eligible for the study would be assigned treatment accordingly by a research assistant. By this process, the research assistant, the doctor, and the patient would not know the specifics of the study drug.
Study Procedure: Patients diagnosed with pulmonary tuberculosis started with category I antitubercular drugs according to their body weight. Patients were randomized to one of the two study groups, in a 1:1 ratio, in 10 blocks of 10 each, using a computer-generated random number list. They took either Silybon $140 \mathrm{mg}$ or Placebo twice daily after food, for 8 weeks along with Category I ATT drugs. Both study drugs were donated, on request, by Micro Labs Limited located at No 31, racecourse road, Bangalore. These were supplied as identical-appearing tablets packaged in airtight, screw cap containers suitable labeled as trial medication. The drugs were coded A or B. Capsule identity was not revealed to the patients or attending investigators. Allocation concealment was achieved using the serially numbered, opaque, sealed envelope technique. The randomization list and the code-breaking authority were retained by a senior pharmacologist not directly interacting with the participants. Patients were followed up at 4 and 8 weeks from the start of the treatment. Group one was received Silymarin containing tablets (Silybon 140). Each Silybon 140 tablet contains dried extract of Silybum marianum equivalent to $140 \mathrm{mg}$ Silymarin. The second group has received a placebo. Study subjects were emphasized to make records when taking anti-tuberculosis and study drugs. The remaining pills were counted on the days of follow-up to check patient compliance and adherence.

Outcome: Primary outcome of the study was to determine the LFT values in 4 and 8 weeks after treatment. The secondary outcome was the development of antitubercular drug-induced liver injury which was defined as

1. Asymptomatic serum transaminase elevation to more than 5 times the upper limit of normal.

2. Serum bilirubin level $>1.5 \mathrm{~g} / \mathrm{dl}$

3. Serum transaminase elevation in association with symptoms such as anorexia, nausea, vomiting, abdominal discomfort, and increased fatigability 
4. Any rise in liver enzymes less than the mentioned cut-off as "mild elevation of LFT".

\section{Statistical Analysis}

Data were entered in Microsoft Excel and data analysis was done using Statistical Package for Social Science (SPSS) 16 software. Data were analyzed based on the intention to treat analysis approach. Mean and Standard Deviation (SD) were derived for continuous data and frequency for categorical data. Descriptive statistics, percentages were used for analysis. Paired, unpaired T-test was used to compare quantitative variables within and between the groups respectively. p-value of 0.05 was taken as statistically significant.

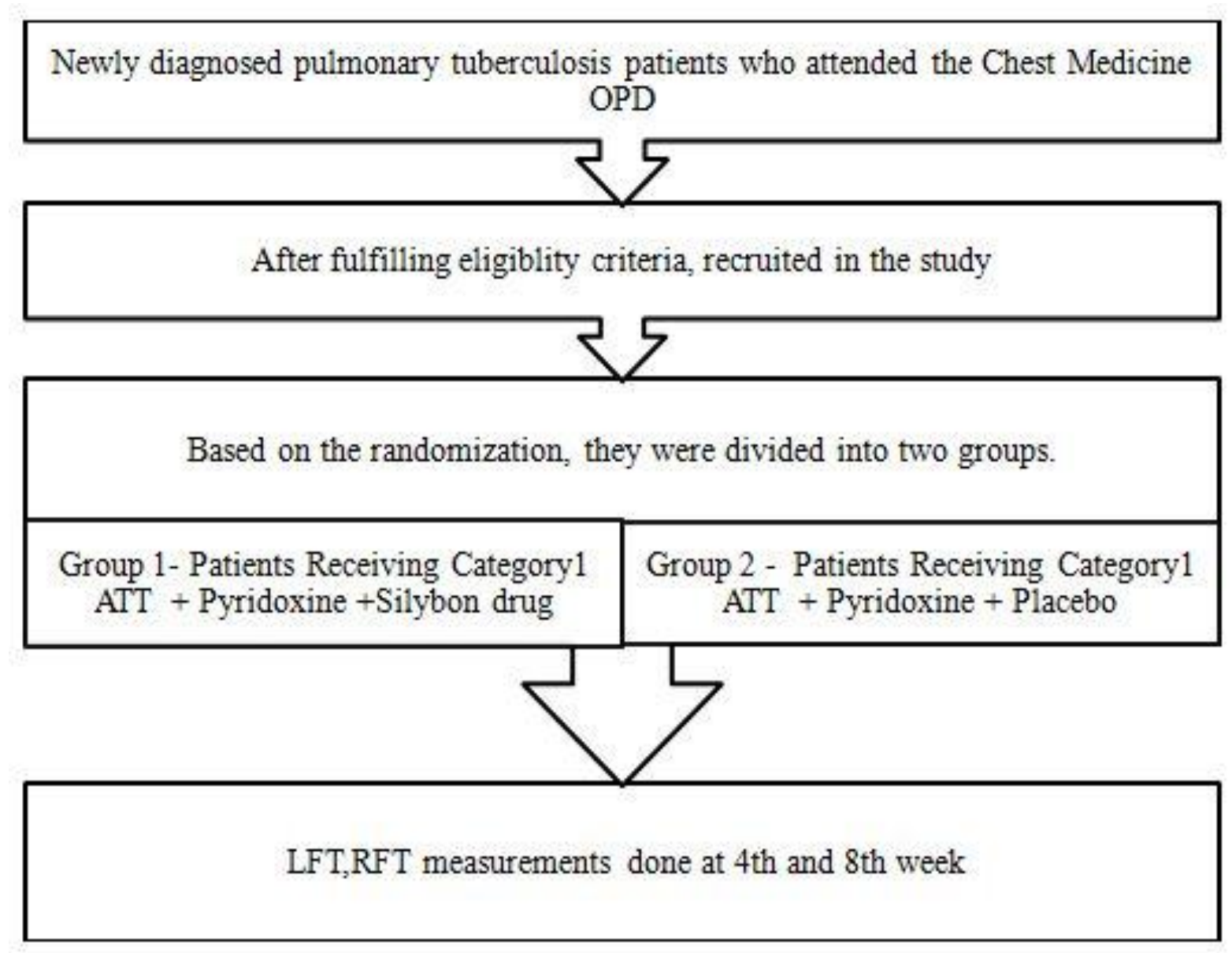

Fig.1.Flow chart- Study procedure

\section{Results}

In this study, 92 patients were enrolled with 46 patients in each group. 2 patients in group 1 (silymarin group) and 3 patients in group 2 (placebo group), were not completing a single follow-up visit. 2 patients in group 1 and 2 patients in group 2 were not taking drugs properly. These patients were excluded from the study and the remaining patients were followed up for 8 weeks. Thus, 42 patients in group 1 (silymarin group) and 41 patients in group 2 (placebo group) completed the study entirely.

The demographic details of the patients in each group are shown in the table 
Table.1. Baseline Characteristics

\begin{tabular}{|c|c|c|c|c|}
\hline S. No & $\begin{array}{c}\text { Baseline } \\
\text { Characteristics }\end{array}$ & $\begin{array}{c}\text { Group I } \\
(\text { silymarin) } \\
(n=42) \\
\text { Mean } \pm \text { S.D } \\
\end{array}$ & 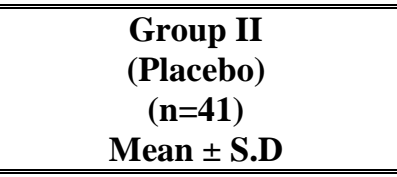 & p-value \\
\hline 1. & Age (Years) & $44.47 \pm 10.73$ & $45.29 \pm 12.46$ & 0.75 \\
\hline \multirow{2}{*}{2.} & \multirow{2}{*}{ Sex } & Female (14) (33.3\%) & Female (12) (29.3\%) & \multirow{2}{*}{0.81} \\
\hline & & Male $\quad(28)(66.7 \%)$ & Male $\quad(29)(70.7 \%)$ & \\
\hline 3. & Height $(\mathrm{cm})$ & $162.64 \pm 6.55$ & $163.78 \pm 6.89$ & 0.44 \\
\hline 4. & Weight $(\mathrm{kg})$ & $43.85 \pm 6.66$ & $46.97 \pm 8.22$ & 0.06 \\
\hline 5. & BMI & $16.55 \pm 2.04$ & $17.47 \pm 2.30$ & 0.058 \\
\hline \multirow{4}{*}{6.} & \multirow{4}{*}{$\begin{array}{c}\text { Socio-economic status } \\
\text { Modified } \\
\text { Kuppuswamy } \\
\text { scale }\end{array}$} & Upper class - nil & Upper class - nil & \multirow{4}{*}{0.737} \\
\hline & & U Upper middle (4) $(9.5 \%)$ & Upper middle (5) (12.2\%) & \\
\hline & & $\begin{array}{c}\text { Lower middle (20) } \\
(47.6 \%)\end{array}$ & Lower middle (16) (39\%) & \\
\hline & & Upper lower (18) (42.9\%) & Upper lower (20) (48.8\%) & \\
\hline
\end{tabular}

In this study, There was no significant difference seen in the age, BMI, and socio-economic status of the patients between two groups. Both groups were comparable in terms of age, gender, BMI, and socioeconomic status.

Table 2. Baseline LFT Values

\begin{tabular}{|c|c|c|c|}
\hline Parameters & $\begin{array}{c}\text { Group 1 } \\
\text { (Silymarin) } \\
(\mathrm{n}=42) \\
\text { Mean } \pm \text { S.D }\end{array}$ & $\begin{array}{c}\text { Group 2 } \\
\text { (Placebo) } \\
(\mathrm{n}=41) \\
\text { Mean } \pm \text { S.D }\end{array}$ & p-value \\
\hline Indirect bilirubin & $0.37 \pm 0.14$ & $0.34 \pm 0.15$ & 0.361 \\
\hline $\begin{array}{l}\text { Direct bilirubin } \\
\end{array}$ & $0.22 \pm 0.09$ & $0.27 \pm 0.08$ & 0.216 \\
\hline Total bilirubin & $0.59 \pm 0.17$ & $0.54 \pm 0.19$ & 0.190 \\
\hline Alanine transaminase & $19.19 \pm 7.21$ & $19.09 \pm 5.35$ & 0.947 \\
\hline Aspartate transaminase & $20.35 \pm 6.93$ & $21.95 \pm 7.31$ & 0.311 \\
\hline Alkaline phosphatase & $45.07 \pm 8.60$ & $44.73 \pm 10.83$ & 0.311 \\
\hline
\end{tabular}

Table 3. LFT Values at 4 Weeks

\begin{tabular}{||l|c|c|c||}
\hline Parameters & $\begin{array}{c}\text { Group 1 } \\
(\text { Silymarin) } \\
(\mathbf{n = 4 2 )} \\
\text { Mean } \pm \text { S.D }\end{array}$ & $\begin{array}{c}\text { Group 2 } \\
(\text { Placebo) } \\
(\mathbf{n = 4 1 )} \\
\text { Mean } \pm \text { S.D }\end{array}$ & p-value \\
\hline \hline Indirect bilirubin & $0.47 \pm 0.15$ & $0.49 \pm 0.16$ & 0.361 \\
\hline \hline Direct bilirubin & $0.24 \pm 0.09$ & $0.27 \pm 0.09$ & 0.209 \\
\hline \hline Total bilirubin & $0.71 \pm 0.18$ & $0.76 \pm 0.20$ & 0.273 \\
\hline \hline Alanine transaminase & $38 \pm 13.05$ & $56.29 \pm 23.13$ & $<0.001$ \\
\hline \hline Aspartate transaminase & $29.5 \pm 13.77$ & $35.17 \pm 14.41$ & 0.07 \\
\hline Alkaline phosphatase & $58.95 \pm 18.43$ & $70.70 \pm 30.4$ & 0.03 \\
\hline
\end{tabular}

Table 4. LFT Values at 8 Weeks

\begin{tabular}{|c|c|c|c|}
\hline Parameters & $\begin{array}{c}\text { Group } 1 \\
\text { (Silymarin) }\end{array}$ & $\begin{array}{c}\text { Group } 2 \\
\text { (Placebo) }\end{array}$ & $P$ value \\
\hline Indirect bilirubin & $0.47 \pm 0.14$ & $0.50 \pm 0.17$ & 0.417 \\
\hline Direct bilirubin & $0.25 \pm 0.10$ & $0.26 \pm 0.11$ & 0.641 \\
\hline Total bilirubin & $0.72 \pm 0.20$ & $0.76 \pm 0.23$ & 0.363 \\
\hline Alanine transaminase & $29.83 \pm 12.7$ & $49.21 \pm 22.29$ & $<<0.001$ \\
\hline Aspartate transaminase & $28.35 \pm 12.35$ & $36.70 \pm 14.41$ & .007 \\
\hline Alkaline phosphatase & $54.83 \pm 16.51$ & $65.65 \pm 31.10$ & .053 \\
\hline
\end{tabular}




\section{JMSCR Vol||08||Issue $\| 10||$ Page 135-146||October}

\section{Indirect Bilirubin}

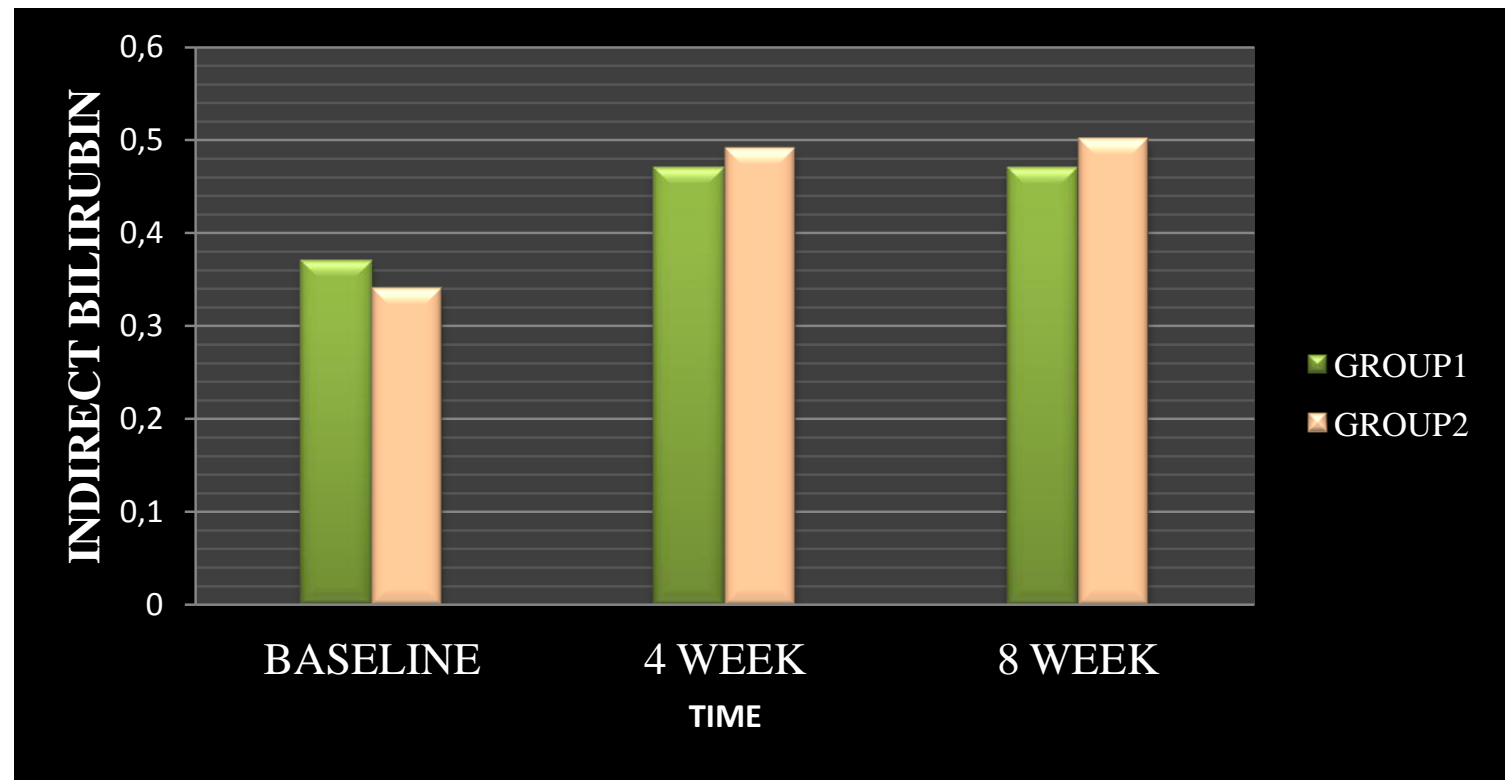

Fig.2.Indirect bilirubin levels

\section{Direct Bilirubin}

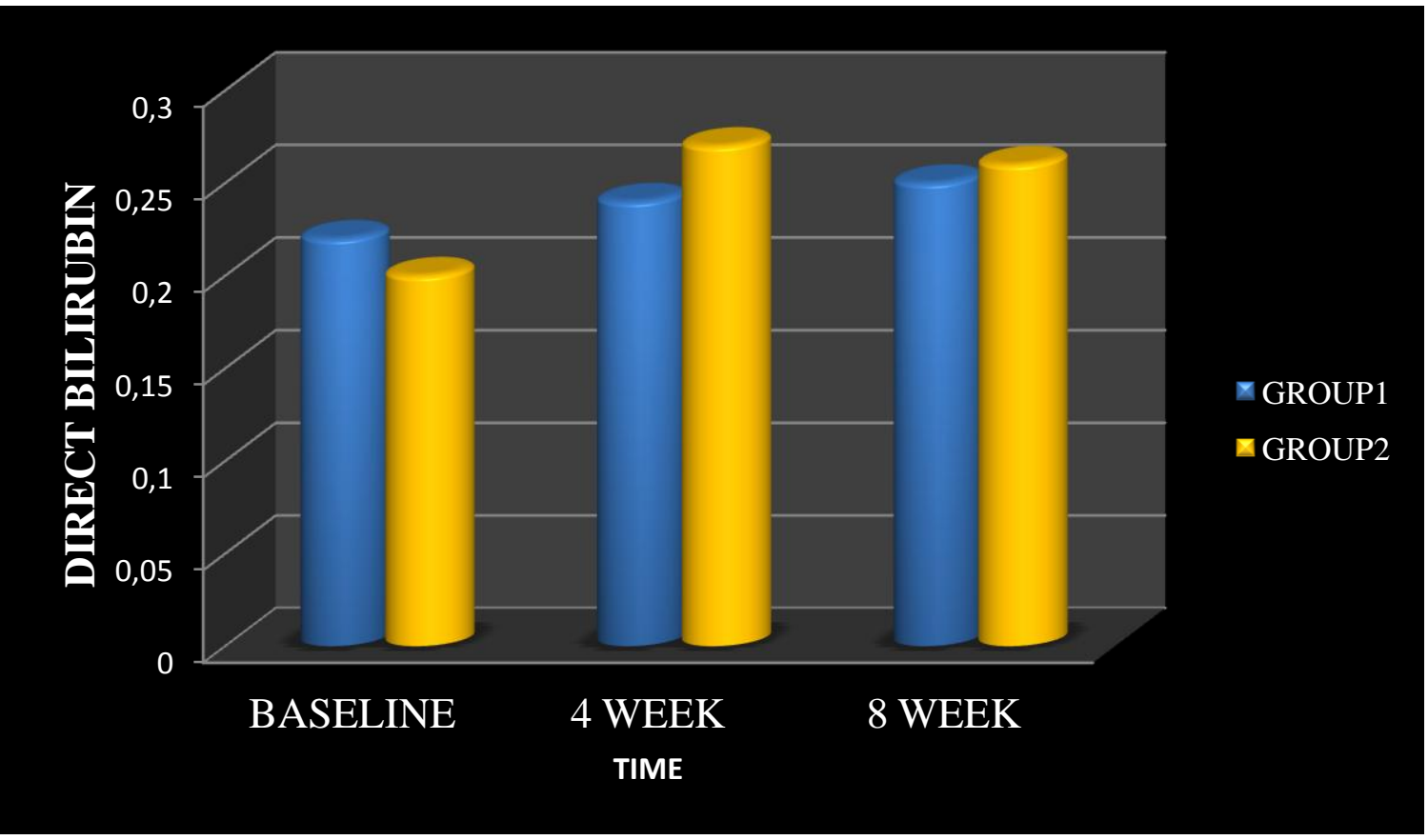

Fig.3.Direct bilirubin levels 


\section{JMSCR Vol||08||Issue\|10||Page 135-146||October}

\section{Total Bilirubin}

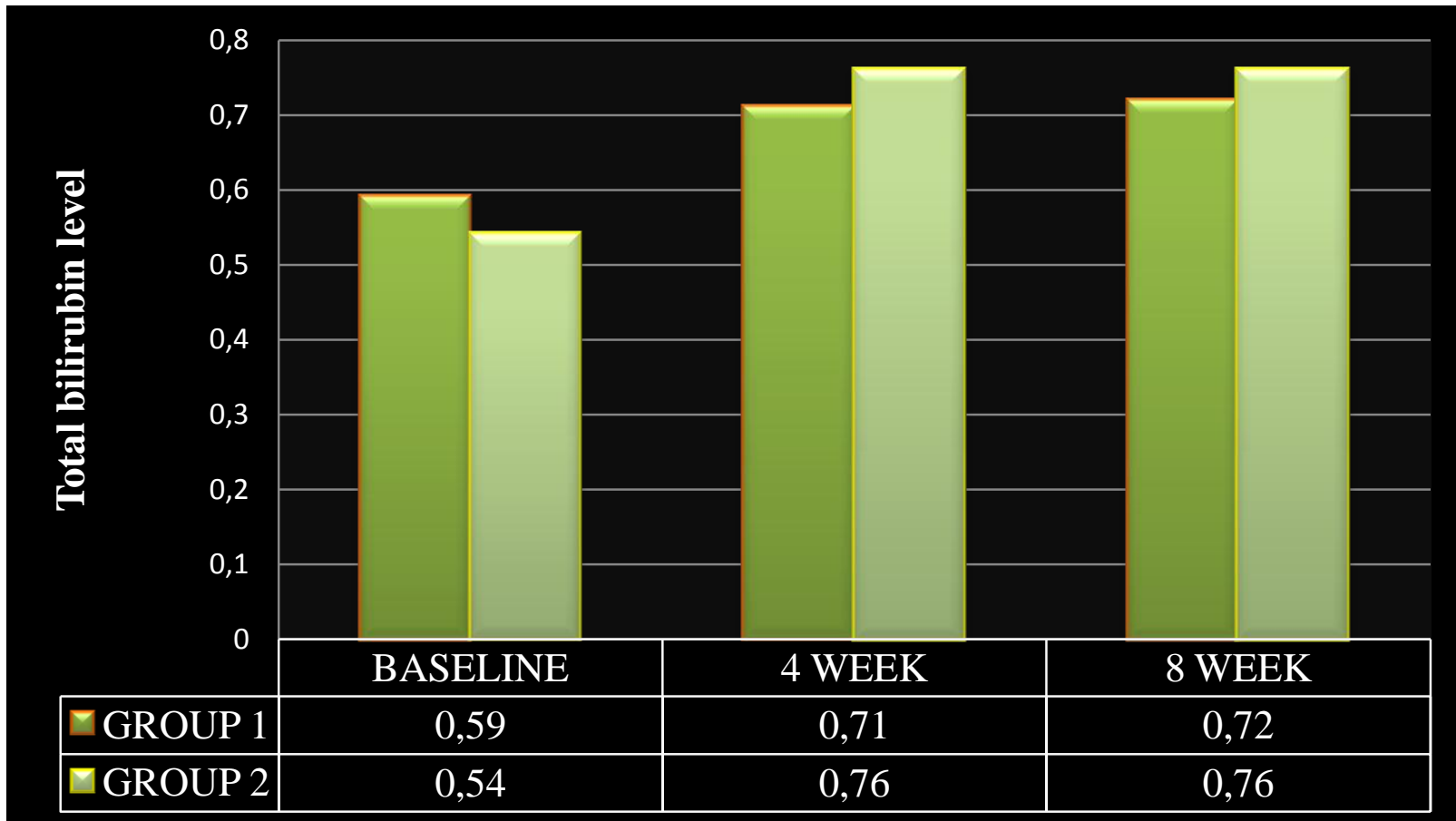

Fig.4. Total bilirubin values

Alanine Transaminase

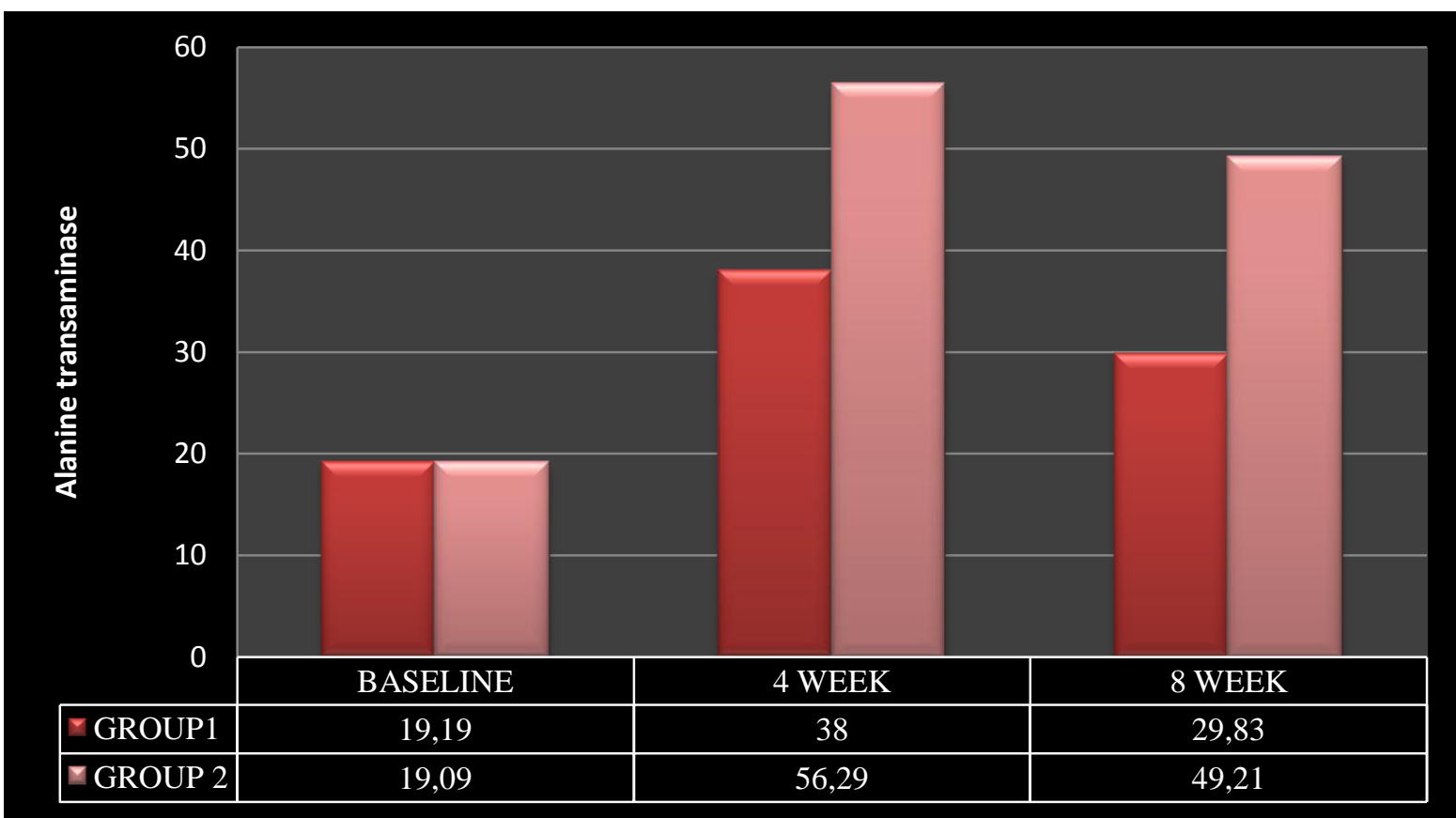

Fig.5.Alanine transaminase levels 


\section{JMSCR Vol||08||Issue $\|10\|$ Page 135-146||October}

\section{Aspartate Transaminase}

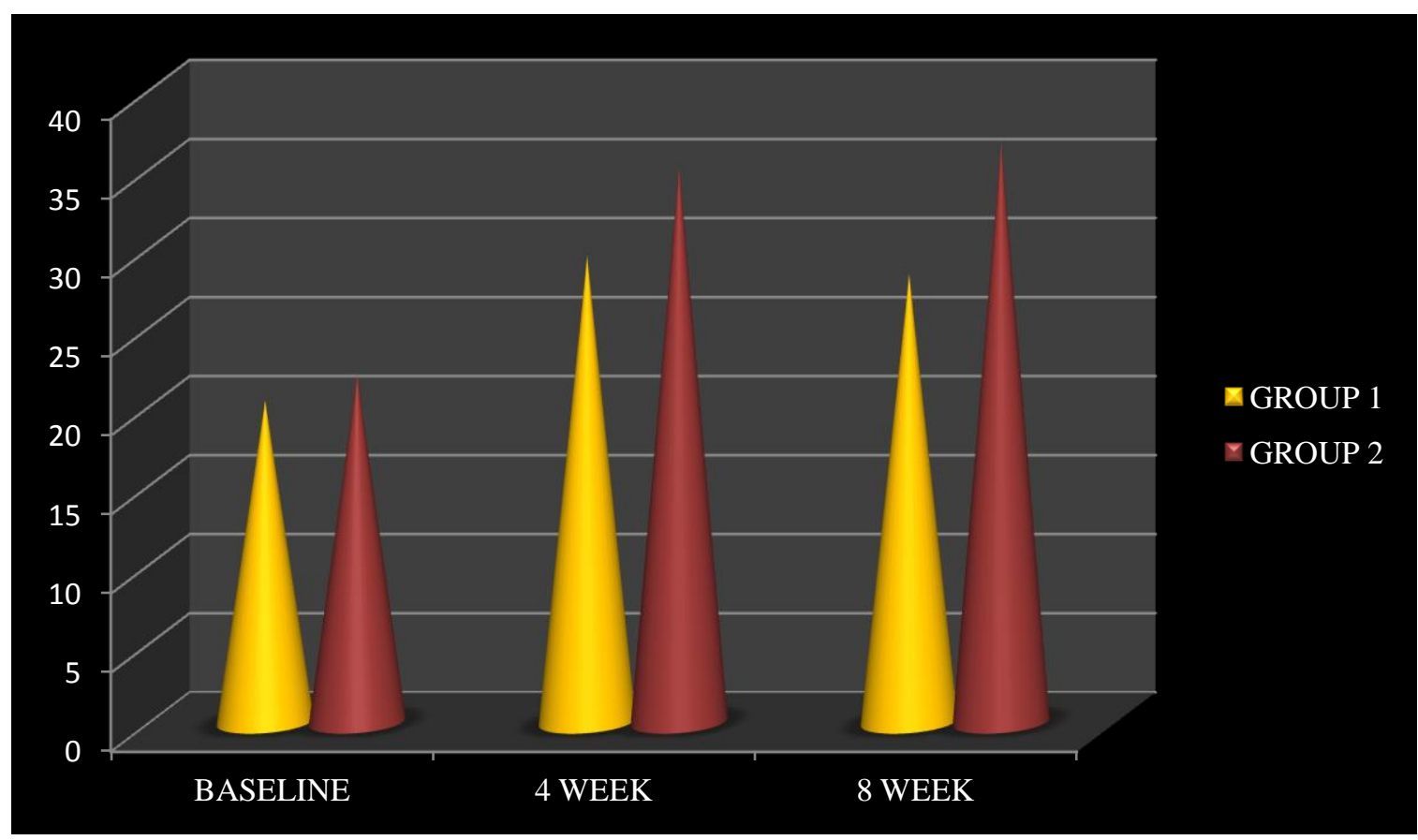

Fig.6. Aspartate transaminase levels

\section{Alkaline Phosphatase}

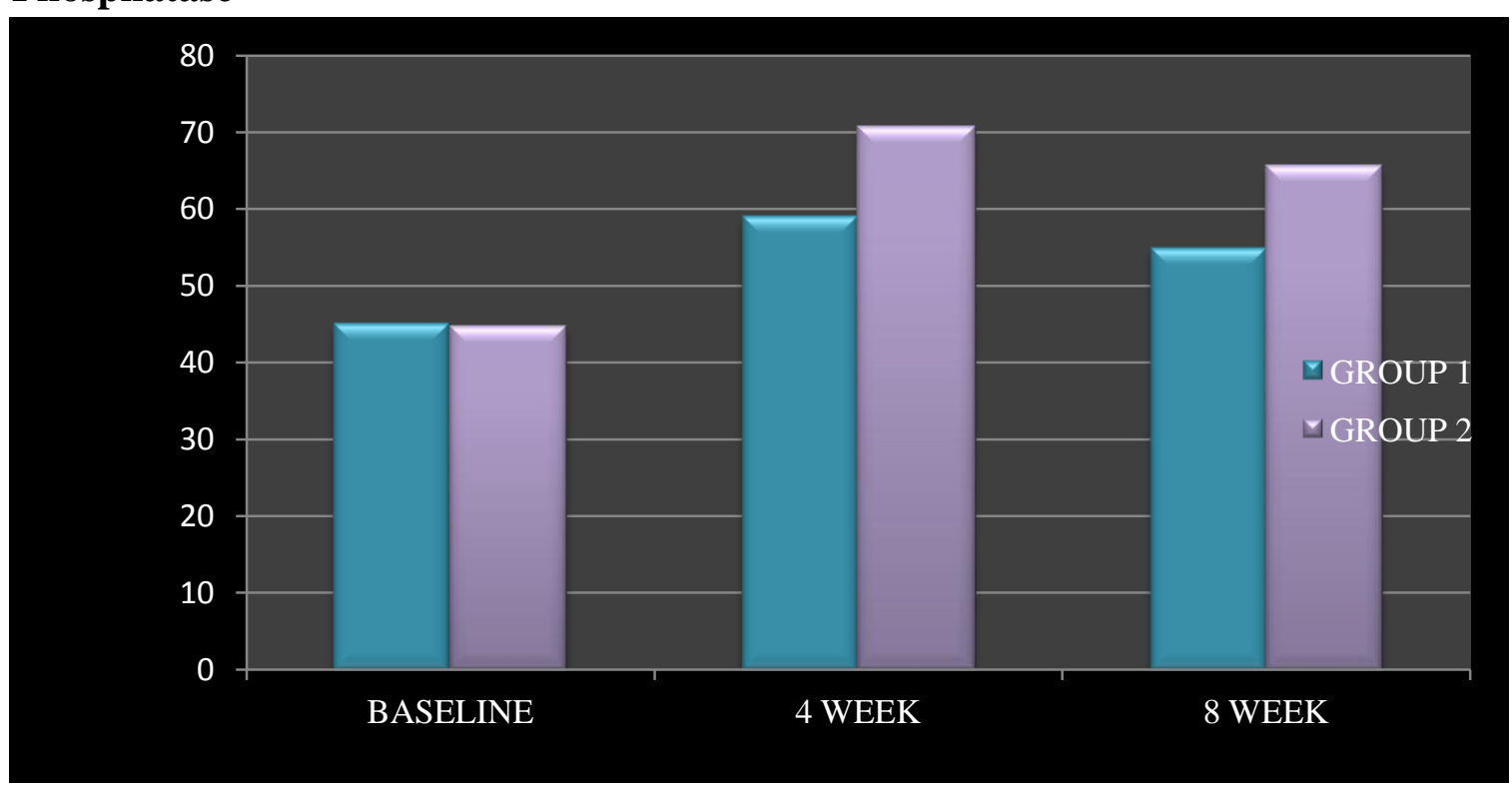

Fig.7. Alkaline phosphatase values

Table. 5. Liver Enzymes Grading at the End of $8^{\text {th }}$ Week

\begin{tabular}{|l|c|c|c|}
\hline Alanine transaminase & Group 1 & Group 2 & P-value \\
\hline \hline With in Normal Limits & $29(69 \%)$ & $11(26.8 \%)$ & \multirow{2}{*}{$<.001$} \\
\hline \hline Mild Elevation & $13(31 \%)$ & $30(73.2 \%)$ & \\
\hline
\end{tabular}

The difference observed between the two groups at the end of the $8^{\text {th }}$ week $(\mathrm{p}$-value $<.000)$ is significant.

\begin{tabular}{|l|c||c||c|}
\hline Aspartate transaminase & Group 1 & Group 2 & P-value \\
\hline \hline With in Normal Limits & $27(64.3 \%)$ & $19(46.3 \%)$ & \multirow{2}{*}{0.1} \\
\hline Mild Elevation & $15(35.7 \%)$ & $22(53.7 \%)$ & \\
\hline
\end{tabular}

The difference observed between the two groups at the end of the $8^{\text {th }}$ week (p-value 0.1 ) is not significant. 


\begin{tabular}{|l|c|c||l||}
\hline Alkaline Phosphatase & Group 1 & Group 2 & P-value \\
\hline With in normal limits & $29(69 \%)$ & $11(26.8 \%)$ & \multirow{2}{*}{$<0.001$} \\
\hline \hline Mild elevation & $13(31 \%)$ & $30(73.2 \%)$ & \\
\hline \hline
\end{tabular}

The difference observed between the two groups at the end of the $8^{\text {th }}$ week (p-value $\left.<.000\right)$ is significant.

Table. 6. Adverse Effects Reported on $4^{\text {th }}$ Week

\begin{tabular}{|r|c||c|c||c|}
\hline \multicolumn{1}{|l|}{ S.No } & Adverse effects & $\begin{array}{c}\text { Group 1 } \\
(\mathbf{n = 4 2})\end{array}$ & Group 2 (n=41) & p value \\
\hline \hline 1. & Nausea & $17(40.5 \%)$ & $31(75.6 \%)$ & 0.002 \\
\hline \hline 2. & Vomiting & $17(40.5 \%)$ & $21(51.2 \%)$ & 0.223 \\
\hline \hline 3. & Abdominal pain & $13(31 \%)$ & $11(26.8 \%)$ & 0.810 \\
\hline \hline. & Yellow sclera & $4(9.5 \%)$ & $5(12.2 \%)$ & 0.738 \\
\hline \hline 5. & Vertigo & $1(2.4 \%)$ & $3(7.3 \%)$ & 0.60 \\
\hline
\end{tabular}

Table.7. Adverse Effects Reported on $8^{\text {th }}$ Week

\begin{tabular}{|r||c|c|c|c|}
\hline \multicolumn{1}{|l|}{ S.No } & Adverse effects & $\begin{array}{c}\text { Group 1 } \\
(\mathbf{n = 4 2})\end{array}$ & $\begin{array}{c}\text { Group 2 } \\
(\mathbf{n = 4 1})\end{array}$ & p value \\
\hline \hline 1 & Nausea & $15(35.7 \%)$ & $31(75.6 \%)$ & $<0.001$ \\
\hline \hline 2 & Vomiting & $10(23.9 \%)$ & $12(29.2 \%)$ & 0.614 \\
\hline \hline 3 & Abdominal pain & $9(21.4 \%)$ & $5(12.1 \%)$ & 0.204 \\
\hline \hline 4 & Yellow sclera & $2(4.8 \%)$ & $4(9.7 \%)$ & 0.433 \\
\hline \hline 6 & Vertigo & 0 & $2(4.9 \%)$ & 0.241 \\
\hline
\end{tabular}

\section{Discussion}

This is the first double-blinded randomized controlled study, from a tertiary care center in India which was planned to evaluate the hepatoprotective activity of silymarin in newly diagnosed pulmonary tuberculosis patients receiving category1 anti-tuberculosis treatment.

The major complication of anti-tubercular treatment (ATT) is drug-induced liver injury (DILI). Approximately 10-25\% of people develop abnormalities in liver function tests (LFTs). ${ }^{[1]}$. The anti-oxidant property of silymarin plays a major role in protecting the liver. ${ }^{[1]}$

A study conducted by Lee et al showed that, out of 1,031 patients, 108 patients $(10.5 \%)$ developed drug-induced hepatotoxicity within 30 days. Among these 108 patients, Twenty-eight patients (25.9\%) developed antituberculous drug-induced hepatotoxicity within 7 days, 73 (67.6\%) within 30 days $^{[17]}$. In our study, silymarin was added during the first 2 months because the incidence of DILI is very common within 4 weeks.

In our study, the maximum number of patients belonged to the age group of $40-60$ years
(67.5\%). In a study conducted by Singla et al, it was found that patients older than 35 years are at 4 times increased risk to develop TB DILI. ${ }^{[16]}$ In our study, the male gender is predominant. There were $57(68.7 \%)$ male patients in the study population. 28 males (66.7\%), 14 females (33.3\%) in silymarin group and 29 males $(70.7 \%), 12$ females $(29.3 \%)$ in placebo group.

Devarbhavi et al conducted a study at St John's Medical College Hospital reported that out of the 313 cases, there were 183 males $(58 \%)$ and 130 females $(42 \%$ )- a finding similar to our study outcome $^{[18]}$.

Poverty and low BMI are the most important risk factors for the development of tuberculosis. ${ }^{[19]} \mathrm{In}$ our study, 67 patients $(80.7 \%)$ were underweight category with BMI less than 18.5.16 patients (19.3\%) were under the normal BMI (18.5 - 25) category. None of the patients had BMI (>25) over the normal range. The socioeconomic status was determined by the modified kuppuswamy scale. 36 patients $(43.4 \%)$ belong to the lower middle class and 38 patients $(45.8 \%)$ belong to the lower class category. The difference between the 
baseline characteristics of the two groups was not significant.

Our study shows the difference between the mean indirect bilirubin, direct bilirubin, and total bilirubin levels in the silymarin group and placebo group at baseline, 4 weeks, and 8 weeks was not significant. In a prospective, randomized, doubleblind, and placebo-controlled study conducted by Heo et al, it was reported that the difference between the mean indirect bilirubin, direct bilirubin, and total bilirubin levels in the silymarin group and placebo group was not significant, a finding similar to our study ${ }^{[20]}$.

In this study, the difference in mean alanine transaminase level in the silymarin group and the placebo group at baseline was not statistically significant. At the end of $4^{\text {th }}$ week, the mean alanine transaminase level in the silymarin group was $38.0( \pm 13.05)$ and the placebo group was $56.29( \pm 23.13)$. The difference observed between the two groups at the end of the $4^{\text {th }}$ week was statistically significant (p-value <0.001). At the end of the $8^{\text {th }}$ week, the mean alanine transaminase level in the silymarin group was $29.83( \pm 12.70)$ and the placebo group was $49.21( \pm 22.29)$. The difference observed between the two groups at the end of the $8^{\text {th }}$ week was statistically significant ( $p$-value $<0.001$ ). In a meta-analysis conducted by Leo et al, silymarin significantly decreased ALT levels compared with placebo groups after 4 weeks of treatment ( $\mathrm{P}$ $=0.003$ ), an outcome similar to our study. ${ }^{[21]}$

The difference in mean aspartate transaminase level in the silymarin group and the placebo group at baseline and at 4 weeks was not statistically significant. At the end of the $8^{\text {th }}$ week, the mean aspartate transaminase level in the silymarin group was $28.35( \pm 12.35)$ and the placebo group was $36.70( \pm 14.41)$. The difference observed between the two groups was statistically significant ( $p$-value $=0.007$ ) in our study. In another study, silymarin significantly decreased AST levels compared with placebo groups after 8 weeks of treatment $(\mathrm{P}=0.008)$, an outcome similar to our study. ${ }^{[21]}$
In our study, the difference in mean alkaline phosphatase level in the silymarin group and the placebo group at baseline and at 8 weeks was not statistically significant. At the end of $4^{\text {th }}$ week, the mean alkaline phosphatase level in the silymarin group was $58.95( \pm 18.43)$ and the placebo group was $70.70( \pm 30.48)$. The difference observed between the two groups was statistically significant ( $\mathrm{p}$-value $=0.03$ ). In a meta-analysis conducted by Leo et al, silymarin significantly decreased alkaline phosphatase levels compared with placebo groups. ${ }^{[21]}$

The adverse reactions seen in both the groups were only mild and most of them were gastrointestinal related symptoms like nausea, vomiting, and gastritis. These adverse events are not specific to silymarin and could occur with anti TB drugs also

\section{Limitations}

This study was done in newly diagnosed pulmonary tuberculosis. The inclusion of patients with extrapulmonary tuberculosis and complicated TB patients would have added more value to this study. Limitations of biomarkers measured in the study - The other potential biomarkers to evaluate the mechanisms of the action of study medications were not measured in the present study. These biomarkers include glutathione peroxidase, superoxide dismutase. They were not measured due to technical constraints. The dose of silymarin is $140 \mathrm{mg}$ twice a day. The dose of silymarin was not increased beyond $140 \mathrm{mg}$ twice a day due to the expected non-compliance of increased gastrointestinal adverse events. Hence further studies with the maximum dose of silymarin may be required to confirm its hepatoprotective effects.

\section{Conclusion}

Drug-induced liver injury frequently occurs in patients on antitubercular drugs. Therefore it is crucial to prevent the incidence of anti-TB DILI as it affects drug compliance and eventually the therapeutic effectiveness. Our study indicated that silymarin produced a notable protective action 
against the hepatotoxicity induced by antitubercular drugs as it significantly reduced ALT levels at weeks 4 and 8 . It also reduced the AST levels at week 4 and ALP levels at 8 weeks. Silymarin also had a good safety profile barring minor adverse effects which required only supportive treatment. However, larger and betterdesigned clinical trials are needed to confirm the outcome of our study before silymarin can be recommended safely to prevent antitubercular drug-induced liver injury.

\section{Acknowledgment}

The authors are grateful to Dhanalakshmi Srinivasan Medical College \& Hospital for supporting the study.

\section{Conflict of Interest}

The authors declare that they have no conflicts of interest.

\section{References}

1. Luangchosiri C, Thakkinstian A, Chitphuk S, Stitchantrakul W, Petraksa S, Sobhonslidsuk A. A double-blinded randomized controlled trial of silymarin for the prevention of antituberculosis drug-induced liver injury. BMC Complement Altern Med [Internet]. 2015;15(1):1-7. Available from: http://dx.doi.org/10.1186/ s12906-015- 08617

2. Asa B. Protective Effects of Silymarin in Isoniazid Induced Hepatotoxicity in Rabbits. Annals [Internet]. 2010;16(1):43-43. Available

from: http://annalskemu.org/journal/index.php/anna 1s/article/view/138

3. Raviglione M, Sulis G. Tuberculosis 2015: Burden, challenges and strategy for control and elimination. Infect Dis Rep. 2016;8(2):33-7.

4. Zumla A, George A, Sharma V, Herbert RHN, Oxley A, Oliver M. The WHO 2014 Global tuberculosis report-further to go. Lancet Glob Heal [Internet]. 2015;3(1):e10-
2.

Available

from:

http://dx.doi.org/10.1016/S2214109X(14)70361-4

5. Arbex MA, Varella M de CL, de Siqueira HR, de Mello FAF. Antituberculosis drugs: Drug interactions, adverse effects, and use in special situations. Part 2: Second-line drugs. J Bras Pneumol. 2010;36(5):641-56.

6. Metushi I, Uetrecht J, Phillips E. Mechanism of isoniazid-induced hepatotoxicity: Then and now. $\mathrm{Br} \mathrm{J}$ Clin Pharmacol. 2016;81(6):1030-6.

7. Daftary A, Frick M, Amico KR, Wolf A, Metcalfe JZ, Isaakidis P, et al. HHS Public Access. Int J Tuberc Lung Dis. 2016;20(4): 430-4.

8. Chiang CY, Van Deun A, Enarson DA. A poor drug-resistant tuberculosis programme is worse than no programme: Time for a change. Int J Tuberc Lung Dis. 2013;17 (6):714-8.

9. Forget EJ, Menzies D. Adverse reactions to first-time antituberculosis drugs. Expert Opin Drug Saf. 2006;5(2):231-49.

10. Kim EJ, Lee MY, Jeon YJ. Silymarin inhibits morphological changes in LPS-stimulated macrophages by blocking NF- $\kappa \mathrm{B}$ pathway. Korean J Physiol Pharmacol. 2015;19 (3):211-8.

11. Senousy BE, Belal SI, Draganov P V. Hepatotoxic effects of therapies for tuberculosis. Nat Rev Gastroenterol Hepatol [Internet]. 2010;7(10):543-56. Available from: http://dx.doi.org/10.1038/nrgastro.2010.134

12. Baghaei P, Tabarsi P, Chitsaz E, Saleh M, Marjani M, Shemirani $S$, et al. Incidence, clinical and epidemiological risk factors, and outcome of drug-induced hepatitis due to antituberculous agents in new tuberculosis cases. Am J Ther. 2010;17(1):17-22.

13. Aithal GP, Watkins PB, Andrade RJ, Larrey $\mathrm{D}$, Molokhia M, Takikawa $\mathrm{H}$, et al. Case definition and phenotype standardization in drug-induced liver injury. Clin Pharmacol 
Ther [Internet]. 2011;89(6):806-15.

Available from: http://dx.doi.org/10.1038/ clpt.2011.58/nature06264

14. Joint Tuberculosis Committee of the British Thoracic Society. Chemotherapy and management of tuberculosis in the United Kingdom: recommendations 1998. Joint Tuberculosis Committee of the British Thoracic Society. Thorax [Internet]. 1998;53(7):536-48. Available from: http://www.pubmedcentral.nih.gov/ articlerender. fcgi? artid=1745276\&tool=pmcentrez\&rendertype $=$ abstract

15. Migliori GB, Raviglione MC, Schaberg T, Davies PDO, Zellweger JP, Grzemska M, et al. Tuberculosis management in Europe. Eur Respir J. 1999;14(4):978-92.

16. Singla R, Sharma SK, Mohan A, Makharia G, Sreenivas V, Jha B, et al. Evaluation of risk factors for antituberculosis treatment induced hepatotoxicity. Indian J Med Res. 2010;132(7):81-6.

17. Lee CM, Lee SS, Lee JM, Cho HC, Kim WS, Kim HJ, et al. Early monitoring for detection of antituberculous drug-induced hepatotoxicity. Korean J Intern Med. 2016;31(1):65-72.

18. Devarbhavi H, Dierkhising R, Kremers WK, Sandeep MS, Karanth D, Adarsh CK. Singlecenter experience with drug-induced liver injury from india: Causes, outcome, prognosis, and predictors of mortality. Am J Gastroenterol [Internet]. 2010;105(11):2396404. Available from: http://dx.doi.org/10.1038/ajg.2010.287

19. Oxlade O, Murray M. Tuberculosis and Poverty: Why Are the Poor at Greater Risk in India? PLoS One. 2012;7(11).

20. Heo E, Kim DK, Oh SH, Lee JK, Park JH, Chung HS. Effect of prophylactic use of silymarin on anti-tuberculosis drugs induced hepatotoxicity. Tuberc Respir Dis (Seoul). 2017;80(3):265-9.
21. Tao L, Qu X, Zhang Y, Song Y, Zhang SX. Prophylactic Therapy of Silymarin (Milk Thistle) on Antituberculosis Drug-Induced Liver Injury: A Meta-Analysis of Randomized Controlled Trials. Can J Gastroenterol Hepatol. 2019;2019. 